\title{
Implicit and Explicit Childhood Financial Socialization: Protective Factors for Marital Financial Disagreements
}

\author{
Ashley Larsen Gibby \\ Brigham Young University - Provo, ashley_gibby@byu.edu \\ Logan Pettit \\ Brigham Young University - Provo \\ E. Jeffrey Hill \\ Brigham Young University - Provo \\ Jeremy Yorgason \\ Brigham Young University - Provo \\ Erin Kramer Holmes

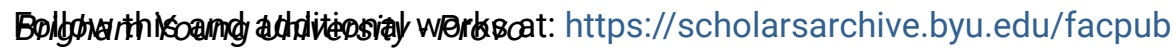 \\ Part of the Other Social and Behavioral Sciences Commons
}

\section{Original Publication Citation}

Gibby, Ashley Larsen, Logan Pettit*, E. Jeffrey Hill, Jeremy Yorgason, and Erin Kramer Holmes. 2020. "Implicit and Explicit Childhood Financial Socialization: Protective Factors for Marital Financial Disagreements." Journal of Family and Economic Issues.

\section{BYU ScholarsArchive Citation}

Gibby, Ashley Larsen; Pettit, Logan; Hill, E. Jeffrey; Yorgason, Jeremy; and Holmes, Erin Kramer, "Implicit and Explicit Childhood Financial Socialization: Protective Factors for Marital Financial Disagreements" (2020). Faculty Publications. 4796.

https://scholarsarchive.byu.edu/facpub/4796

This Peer-Reviewed Article is brought to you for free and open access by BYU ScholarsArchive. It has been accepted for inclusion in Faculty Publications by an authorized administrator of BYU ScholarsArchive. For more information, please contact ellen_amatangelo@byu.edu. 


\title{
Implicit and Explicit Childhood Financial Socialization: Protective Factors for Marital Financial Disagreements
}

\author{
Ashley Larsen Gibby ${ }^{1}\left[\right.$ [D $\cdot$ Logan Pettit ${ }^{2} \cdot$ E. Jeffrey Hill ${ }^{1} \cdot$ Jeremy Yorgason $^{1} \cdot$ Erin Kramer Holmes $^{1}$
}

(c) Springer Science+Business Media, LLC, part of Springer Nature 2020

\begin{abstract}
Research to date has shown that childhood financial socialization is significantly associated with the financial attitudes and behaviors of children, youth, and adults. However, the extent to which childhood financial socialization is connected to marital outcomes remains largely unknown. Using data from 1,473 newly married couples who participated in a nationally representative study, we examined the relationship between childhood financial socialization and reported marital financial disagreements by utilizing actor-partner interdependence structural equation models (APIM SEM). Our results suggest that implicit (i.e. parental modeling) and explicit (i.e. direct conversations or experiential learning) financial socialization significantly and negatively relate to marital financial disagreements for both men and women. Further, having a spouse who was explicitly taught about finances is significantly and negatively associated with financial disagreements, independently of one's own explicit financial socialization. These results highlight the importance of considering marital outcomes in the financial socialization literature and suggest that childhood financial socialization is a protective factor for marital financial disagreements.
\end{abstract}

Keywords Financial socialization $\cdot$ Family finance $\cdot$ Disagreements $\cdot$ Marital conflict $\cdot$ Parental modeling

\section{Introduction}

Research to date has found that financial disagreements are negatively associated with relationship satisfaction (Britt and Huston 2012) and positively associated with divorce, even more strongly than other types of marital disagreements (Dew et al. 2012). Scholars have argued that financial disagreements have a particularly pronounced impact because they are more salient to couples, are harder to resolve, and are typically associated with less effective conflict resolution

This is one of several papers published together in Journal of Family and Economic Issues on the "Special Issue on Couples, Families, and Finances".

Electronic supplementary material The online version of this article (https://doi.org/10.1007/s10834-020-09695-8) contains supplementary material, which is available to authorized users.

Ashley Larsen Gibby

Ashley_gibby@byu.edu

1 School of Family Life, Brigham Young University, Provo, UT, USA

2 Brigham Young University, Provo, UT, USA tactics than those that are employed in other types of disagreements (Dew et al. 2012). Furthermore, discussions about finances are often socially regarded as being taboo or private matters (LeBaron et al. 2018a). Hence, individuals tend to possess fewer skills - whether directly taught to or modeled for them - with which they can navigate financial conflict in marriage. Consequently, we propose that financial socialization in childhood may meaningfully shape the nature of marital financial disagreements.

Financial socialization in childhood may be an important correlate to marital financial disagreements for two major reasons. First, by definition, adults who experienced effective financial socialization as children have been exposed more frequently than those who have not to financial conversations, possibly making these issues less emotionally charged and more commonplace. Thus, adults who experienced financial socialization as children more often have models, social scripts, skills, and reasonable expectations around discussing finances than those who did not. And, second, adults who experienced childhood financial socialization are often more financially competent (e.g., Jorgensen et al. 2017; Kim and Chatterjee 2013). Therefore, any 
financial disagreements likely involve less risk or are taking place within a more stable financial context.

Family scholars have consistently used broad definitions of financial socialization, incorporating both explicit and implicit learning (Gudmunson and Danes 2011). A small body of research has examined the effects of childhood financial socialization on young adults, finding it significantly related to financial behaviors like cash management, capital accumulation, and credit management (e.g., Hancock et al. 2013; Jorgensen et al. 2017). However, no known studies have followed the influence of childhood financial socialization into marriages.

In this study, we argue that childhood socialization is likely related to marital outcomes. Previous research has documented that childhood experiences are crucial to social and emotional development over the life course and specifically influence marital quality and other adult romantic relationships (McCarthy and Maughan 2010; Truant et al. 1987). Therefore, we expand current understanding by examining the relationship between financial socialization and marital outcomes using data from a nationally representative study of newly-married U.S. couples, the Couple Relationships and Transition Experiences (CREATE) project.

\section{Background}

\section{Financial Disagreements}

Previous studies have shown that financial disagreements are strongly related to marital outcomes. Using data from the National Survey of Family and Households, Dew et al. (2012) found that financial disagreements were positively and significantly related to divorce. Moreover, financial disagreements were more strongly associated with divorce than other types of marital disagreements such as those about chores, time together, in-laws, or sex. A handful of other studies that also used nationally representative samples found that financial disagreements are negatively associated with relationship satisfaction (Britt and Huston 2012) and that finances are a commonly cited reason for filing for divorce (Amato and Previti 2003).

Financial disagreements between married couples likely influence marital outcomes because they are, on average, more intense and longer lasting than other forms of disagreements. For example, when examining dyadic data from 100 heterosexual couples, Papp et al. (2009) found that, although couples did not cite financial disagreements as being the most frequently occurring topic of their conflicts, they reported that financial disagreements were more problematic, recurrent, and were more likely to remain unresolved when compared with other forms of marital conflict. Financial disagreements also elicited more negative feelings (e.g., anger) and behaviors (e.g., "angry behaviors", as defined by respondents) than other forms of disagreements. These findings have been supported by the results of several other studies of marital disagreements (e.g., Dew and Dakin 2011; Stanley et al. 2002).

Furthermore, several researchers have identified important gender differences between the behaviors and responses of individuals in the context of financial disagreements. For example, in one study, researchers reported that, although husbands and wives reported similar levels of financial disagreements, husbands' reports of financial disagreements were more strongly related to divorce than wives' reports of financial disagreements (Dew et al. 2012). The authors of this particular study concluded that such differences-seemingly signaling the greater saliency of finances for husbands as compared to wives - could be attributed to the fact that, due to historical and cultural norms, husbands generally have greater power over finances than wives. Similarly, the findings of other studies have indicated that husbands' reports of financial disagreements were more strongly related to conflict resolution tactics than wives' reports (Dew and Dakin 2011). And, when asked to provide a list of important and problematic topics or issues within their marriages, husbands tended to rank money at a higher position on the list than their wives (Papp et al. 2009).

\section{The Role of Childhood Financial Socialization}

One possible explanation for the unique intensity of financial disagreements is the taboo nature of discussions about money (Solheim et al. 2011). Many college students, when reflecting on their upbringing, indicated that they learned, or had been taught, that money was a "secret, private matter" (p. 106). At the extreme, some students reported that their parents had implied that discussions about finances were inappropriate, even among spouses. This type of taboo stigmatization inhibits children from learning skills, scripts, or models with which they can engage in healthy financial discussions.

Social learning theory posits that children learn by observing and mimicking the behaviors of those who are like them, those who are high in status, and those who are nurturing (Grusec and Hastings 2014). Although many individuals can function as socializers, including romantic partners (Curran et al. 2018; Serido et al. 2015), family finance scholars recognize parents as "primary" socializers (Serido and Deenanath 2016). This status is afforded to parents due to biological predispositions, societal expectations, the conventional proximity of a parent to their child, and parental control over children's material and economic resources (Gudmunson and Danes 2011, p. 646). Consequently, a substantial body of literature has examined the nature of childhood financial socialization, focusing on parents, and 
its relation to financial behaviors and attitudes through adulthood (for a review see Gudmunson and Danes 2011). This perspective, financial socialization, adapted social learning theory to explain this nuanced, specific phenomenon: the transfer of financial behaviors and attitudes.

Childhood financial socialization is defined broadly in this literature. In a thorough review on family financial socialization, Gudmunson and Danes (2011) posed the following as the "spearhead" definition: "processes by which young people acquire skills, knowledge, and attitudes relevant to their functioning as consumers in the marketplace" (Ward 1974, p.2). This definition does not include specific age criteria. However, for the purpose of this study, we focus on children, defining a "child" as any individual who is under the age of 18. The aforementioned definition of financial socialization refers to both implicit and explicit (or purposive) socialization: an important distinction that has been made in past literature (Gudmunson and Danes 2011; LeBaron et al. 2018c).

Implicit financial socialization, or role-modeling, has been noted as likely the most prevalent form of socialization (Serido and Deenanath 2016). The term is used to describe parents who model certain financial behaviors without intentionally teaching these behaviors or skills to their children. Examples of implicit financial socialization include parents demonstrably working for money, avoiding debt, or budgeting. For example, a respondent in one qualitative study described the experience of watching her mother input grocery receipts, among other things, into a Microsoft Excel spreadsheet daily in order to ensure that she adhered to her budget (Rosa et al. 2018). The respondent asserted that her mother had never deliberately drawn her daughter's attention to the spreadsheet or explicitly discussed or taught her how to budget effectively. Nonetheless, through her mother's example, the respondent learned how to budget. Similarly, implicit socialization can also include the example of parents talking to or arguing with each other about finances without intentionally involving their children in their dispute (Rosa et al. 2018). In this instance, children learn how to (mis)manage financial conversations through their parents' example.

Implicit financial socialization is significantly associated with financial behaviors. Implicit socialization is, for example, positively and significantly associated with cash management (e.g., budgeting), credit management (i.e., credit card possession, payments, and the avoidance of debt), capital accumulation (e.g., saving and investment behavior), and general management (e.g., long-term planning and assessment) (Hibbert et al. 2004; Jorgensen et al. 2017). Furthermore, these associations are relatively strong. Having parents who fought about money, for example, was more strongly associated with the number of credit cards college students' held than the nature of their work experience, their level of financial knowledge, and their personal attitudes towards having and using credit cards (Hancock et al. 2013).

Alternatively, explicit financial socialization refers to deliberate interactions and discussions between parents and children about finances. This largely includes family conversations about money, whether initiated by a parent or a child, and forms of experiential learning such as children making their own money or creating a budget (LeBaron et al. 2018c). Explicit financial socialization has a significantly stronger association with financial attitudes and behaviors than implicit financial socialization (e.g., Jorgensen and Savla 2010). This is likely because there is a greater risk of implicit teaching content being misinterpreted (Serido and Deenanath 2016). Explicit financial socialization has been significantly linked to an individual's ownership of financial assets and their possession of a positive attitude towards personal finances (Kim and Chatterjee 2013), as well as their maintenance of higher credit scores and lower levels of credit-card debt (Grinstein-Weiss et al. 2011; Norvilitis and MacLean 2010) and a tendency to exhibit saving behaviors and set financial goals (Koonce et al. 2008; Webley and Nyhus 2006).

With regard to both implicit and explicit socialization, most studies that have examined childhood financial socialization to date have explored its relationship to children's or young adults' financial behaviors or attitudes (e.g., Hancock et al. 2013; Hibbert et al. 2004; Jorgensen et al. 2017; Jorgensen and Salva 2010; Kim and Chatterjee 2013). We argue that childhood financial socialization may be similarly related to marital outcomes for two major reasons.

First, financial socialization, by its very nature, exposes children to financial conversations, either deliberately or through example. Therefore, children who report that they have experienced financial socialization have, at a minimum, watched other adults discuss finances, thereby normalizing these interactions. Even if only through example, these types of interactions and forms of modeling can be powerful (Grusec and Hastings 2014). Explicit socialization teaches children - to an even greater degree - how to have purposive conversations about finances; it exposes them to financial conversations that are not emotionally charged (LeBaron et al. 2018c, 2020). As such, explicit socialization affords children with access to models, skills, and scripts upon which they can draw when navigating financial matters throughout their lives, including in their marriages.

Second, financial socialization in childhood, especially explicit financial socialization, relates closely to an individual's financial competency and stability in adulthood (e.g., Hancock et al. 2013; Jorgensen et al. 2017). Therefore, adults who report having experienced financial socialization in their youth are likely to be in better financial situations than those who do not. Consequently, the financial discussions that take place within the marriages 
of those who have been effectively financially socialized in their childhoods are likely to be lower-risk and may lead to fewer or less intense disagreements.

We acknowledge that it is likely that much of this association is due to socioeconomic status, in that those who have a higher socioeconomic status are more likely to possess considerable financial knowledge and to have access to a myriad of financial institutions (Johnson and Sherraden 2007). However, previous studies have not been able to adequately address this issue. This is, in large part, because samples have typically been limited to college students (e.g., Hancock et al. 2013; Hibbert et al. 2004; Jorgensen et al. 2017; Jorgensen and Savla 2010; Serido et al. 2015). The data set that we have used in this study enables us to isolate this association more fully by accounting for differences in socioeconomic status.

\section{The Present Study}

Based on our review and interpretation of the existing literature that pertains to family financial socialization theory, we hypothesize that implicit and explicit childhood financial socialization will be significantly and negatively associated with marital financial disagreements for both men and women. We further anticipate that this relationship will be stronger for explicit financial socialization. Differentiating this study from previous studies on this topic, we will explore both actor and partner effects. We will further explore differences in these relationships by gender.

This study fills an important gap in the literature by expanding family financial socialization scholarship to the examination of marital outcomes. Moreover, our use of a nationally representative data set on newly married couples allows for a more generalizable examination of childhood financial socialization.

\section{Data and Methods}

We used data from the Couple Relationships and Transition Experiences (CREATE) project: a longitudinal project that was designed to examine how marital relationships develop over time (Yorgason et al. 2018). CREATE followed a nationally representative, random sample of 2,187 newlymarried (married between 2013 and 2015) couples for three years (2016-2019). CREATE selected their participating couples by using a two-stage cluster stratification sample design. The first stage was to sample counties; the second stage involved sampling newly-married couples within those counties by using publicly available marriage records.

\section{Sample}

We utilized data from Wave 3, the only wave in which financial disagreement measures were collected. Over the course of the study, couples dissolved, and some individuals re-coupled. For the purposes of this study, we focused only on couples who were originally sampled, excluding new partners $(n=12)$. Wave 3 included 1,536 couples in which both of the spouses had completed the questionnaire. We excluded same-sex couples $(n=63)$ so that we could more fully explore the gendered nature of these processes, matching the approach of previous studies (e.g., Dew et al. 2012), and because we did not have enough same-sex couples to be able to fully explore their variability. However, we conducted sensitivity analyses which included same-sex couples; we have described those results below. Our analytic sample included 1,473 heterosexual couples.

\section{Measures}

\section{Dependent Variables}

We measured both wives' and husbands' reports of financial disagreements by using three survey items. The first asked respondents, "How often in the last year have you had open disagreements about money with your spouse?" with response options $1=$ never; $2=$ once or twice; $3=\mathrm{a}$ few times; $4=$ about once a month; $5=$ about once a week; $6=$ several times a week or more. The second asked, "How well are you and your spouse able to communicate about money?" with response options $1=$ extremely well; $2=$ very well; $3=$ okay; $4=$ not very well; $5=$ not well at all. And the third survey item measured how much respondents agreed with the following statement "Our finances strain our marriage," with response options $1=$ strongly agree; $2=$ agree $3=$ somewhat agree $4=$ neither agree nor disagree; $5=$ somewhat disagree; $6=$ disagree; $7=$ strongly disagree. We reverse coded the third item so that it would match the other two financial disagreement measures. These three measurements had high internal reliability $(a=0.77)$. We estimated these variables in our SEM model as latent variables separately for husbands and wives in order to create financial disagreements constructs. We used mean scores to report descriptive statistics for these variables, as presented in Table 1.

\section{Primary Independent Variables}

We measured financial socialization for husbands and wives. Respondents were asked, "How would you describe how finances were communicated in your family?" and had the following response options $1=$ my parents usually argued about the finances; $2=$ my parents explicitly taught me about 
Table 1 Percentages and Means of Characteristics of NewlyMarried, Heterosexual Couples, 2018, United States $(N=1,473)$

\begin{tabular}{|c|c|c|c|}
\hline & \multicolumn{2}{|c|}{ Mean or percent } & \multirow[b]{2}{*}{ Significantly different ${ }^{\mathrm{a}}$} \\
\hline & Wives & Husbands & \\
\hline \multicolumn{4}{|l|}{ Individual characteristics } \\
\hline Financial disagreements scale $(0-6)$ & 2.59 & 2.54 & $-1.97 *$ \\
\hline \multicolumn{4}{|l|}{ Childhood financial socialization } \\
\hline None & 26.54 & 26.23 & -0.30 \\
\hline Implicit & 44.59 & 48.85 & $1.97 *$ \\
\hline Explicit & 28.87 & 24.92 & -1.90 \\
\hline Age & 29.70 & 31.68 & $-15.95 * * *$ \\
\hline Previously married & 7.20 & 9.37 & $-2.05^{*}$ \\
\hline \multicolumn{4}{|l|}{ Education } \\
\hline Some college or more & 87.29 & 77.84 & $8.47 * * *$ \\
\hline \multicolumn{4}{|l|}{ Race } \\
\hline White & 68.01 & 67.55 & -0.74 \\
\hline Black & 6.95 & 8.62 & $3.66 * *$ \\
\hline Latino & 11.82 & 11.56 & -0.18 \\
\hline Other & 13.21 & 12.26 & -0.74 \\
\hline Employed & 74.07 & 92.60 & $-13.96 * * *$ \\
\hline \multicolumn{4}{|l|}{ Couple characteristics } \\
\hline Months married at Wave 1 & 15.41 & - & - \\
\hline Number of children & 1.25 & - & - \\
\hline Annual household income over $\$ 70,000$ & 53.19 & - & - \\
\hline Joint bank account & 82.47 & - & - \\
\hline
\end{tabular}

Data: Couple Relationships and Transition Experiences (CREATE), Wave 3

$* p<0.05 ; * * p<0.01 ; * * * p<0.001$

${ }^{a}$ Determined by paired sample t-tests; $\mathrm{t}$-values reported finances (e.g., credit cards, debt, budgeting, savings); $3=$ we didn't talk much about finances but I learned (implicitly) from their examples; and 4=I didn't learn about finances from my parents implicitly or explicitly. Participants were permitted to select more than one response. We created a categorical variable measuring whether respondents had reported no financial socialization (0), implicit financial socialization (1), or explicit financial socialization (2). We have not accounted for whether respondents' parents usually argued about finances in the presented analysis. We did, however, include that as a dichotomous control variable ( 1 = "parents argued about finances"; $0=$ "they did not") in sensitivity analyses and substantive results remained similar to what we have presented in this study (see Table A3 in the online appendix).

\section{Control Variables}

We accounted for individual-level and couple-level characteristics that are likely associated with financial socialization and financial disagreements. We measured the age of both husbands and wives in years and whether they had been previously married ( 1 = had been previously married; $0=$ had not been previously married). Further, economic advantage gives families greater ability to teach and demonstrate financial principles (Gudmunson and Danes 2011). Therefore, to account for this discrepancy, we accounted for family advantages. We accounted for the education ( $1=$ some college or more; $0=$ less than some college), race ( $1=$ White; $2=$ Black; 3 =Latino; $4=$ other $)$ and employment status $(1=$ employed; $0=$ not employed) of both husbands and wives.

In terms of couple characteristics, we controlled for the number of months for which a couple had been married when they entered the study, their number of children, and whether their annual household income was above the median household income for the study $(1=\$ 70,000$ or higher; $0=$ lower than $\$ 70,000)$. It was particularly important for us to account for income. Previous studies have shown that income is positively and significantly associated with marital outcomes (e.g., Gibson-Davis 2009). Moreover, because past studies have shown that the sharing of a joint bank account by spouses is significantly associated with higher levels of relationship quality - especially for women (e.g., Addo and Sassler 2010) - we accounted for whether or not couples had a joint bank account $(1=$ any bank account is joint; $0=$ no bank account is joint). We measured number of children, income, and having a joint bank account by using wives' 
reports, rather than husbands', because husbands' and wives' reports were strongly correlated $(r>0.7)$.

None of the included variables were strongly correlated (see Table A1 in the online appendix). The most strongly correlated variables were wives' and husbands' reports of financial disagreements $(r=0.6)$, race $(r=0.5)$, education $(r=0.4)$ and age $(r=0.6)$, as well as the ages of wives and whether or not wives had previously been married $(r=0.3)$, and the ages of husbands and whether or not husbands had previously been married $(r=0.4)$.

\section{Analytic Strategy}

First, we reported descriptive statistics (means and percentages) across all the included variables for husbands and wives. We then estimated actor-partner interdependence structural equation models (APIM SEM) in Mplus Version 8 (Muthén and Muthén 2017). We chose this model over others, like OLS regression, because this model allowed us to test all paths together in one model (testing more accurately for both actor and partner effects), use latent variables, account more accurately for measurement error, and assess model fit (Kenny et al. 2006; Muthén and Muthén 2017). Our adoption of this approach included two steps. First, we created models in SEM to examine factor loadings and the model fit of latent constructs for financial disagreements. Our dependent variables - namely, financial disagreements reported by wives and husbands - were the only latent constructs that we used our models to estimate. We tested measurement invariance in financial disagreement across spouses and the results indicated that no measurement properties were invariant (Wald test of parameter constraints testing factor loading invariance $=15.62(3), p=0.001)$. As such, we did not include any measurement constraints in our later models.

Second, by using the measurements that we had created during the first step, we estimated APIM SEM models to test both actor effects (e.g., wives' financial socialization on wives' reports of financial disagreements) and partner effects (e.g., husbands' financial socialization on wives' reports of financial disagreements). We estimated both wives' and husbands' reports of financial disagreements as dependent variables. No included variable was missing more than $15 \%$ of cases. We accounted for missing data by using the full information maximum likelihood method (FIML) in SEM, which is comparable to multiple imputation (Newman 2003). FIML does not include missing cases on model predictors but does allow missing data on model outcomes. For all models, we utilized the couple as the unit of analysis, accounted for couple-level non-independence through covariances across partner variables, and employed sampling weights. Model fit for our APIM SEM models fell within acceptable bounds (Hu and Bentler 1999; $\chi^{2}=2501.37$ (147), $\mathrm{p}=0.000$;
Comparative Fit Index $(\mathrm{CFI})=0.95$; Root Mean Square Error of Approximation $($ RMSEA) $=0.03$ (lower $\mathrm{CI}=0.025$, upper $\mathrm{CI}=0.035)$ ).

\section{Results}

Our descriptive results show that both wives and husbands reported relatively low levels of financial disagreements (see Table 1). Wives reported a slightly higher average on the scale of financial disagreements (2.6) than husbands (2.5), and this difference was statistically significant $(p<0.05)$. In terms of childhood financial socialization, both husbands and wives reported similar levels of having either experienced no financial socialization or explicit socialization. About one fourth (26\%) of both husbands and wives reported that they had experienced no financial socialization, whereas about $29 \%$ of wives and $25 \%$ of husbands reported having experienced explicit financial socialization. Alternatively, more husbands (49\%) than wives $(45 \%)$ reported having implicitly been financially socialized by, or through, their parents. This difference was statistically significant $(p<0.05)$.

We also found notable demographic differences between husbands and wives. For example, husbands were significantly older than wives, on average (the mean age for husbands was 32 years old while it was 30 years old for wives) and were more likely to have been previously married than wives (9\% of husbands had been married before versus $7 \%$ of wives). Wives were, in contrast, more likely to have undertaken some college education than husbands ( $87 \%$ of wives versus $78 \%$ of husbands), and this difference was statistically significant $(p<0.001)$. Our findings regarding race were very similar for husbands and wives - most respondents (about $68 \%$ of both husbands and wives) were white, about $12 \%$ were Latino, and $13 \%$ identified as another race. The only statistically significant difference that we found between husbands and wives was among Black respondents; $7 \%$ of wives were Black in comparison to $9 \%$ of husbands. Unsurprisingly, husbands were more often employed (93\%) than wives (74\%). On average, at the time of first entering the survey, couples had been married for approximately 15 months and had one child. Around $82 \%$ of couples reported having at least one joint bank account.

Our APIM SEM results unambiguously supported our hypotheses that childhood financial socialization would be significantly and negatively related to marital financial disagreements. Both implicit and explicit forms of childhood financial socialization were significantly and negatively associated with reported marital financial disagreements for men and women (see Fig. 1). In Fig. 1, we present standardized coefficients from the full model. Wives who reported implicit $(b=-0.08)$ or explicit $(b=-0.11)$ financial 
Fig. 1 Actor-Partner interdependence structural equation model (APIMSEM) of Wives' and Husbands reports of financial disagreements and financial socialization $(N=1,473)$

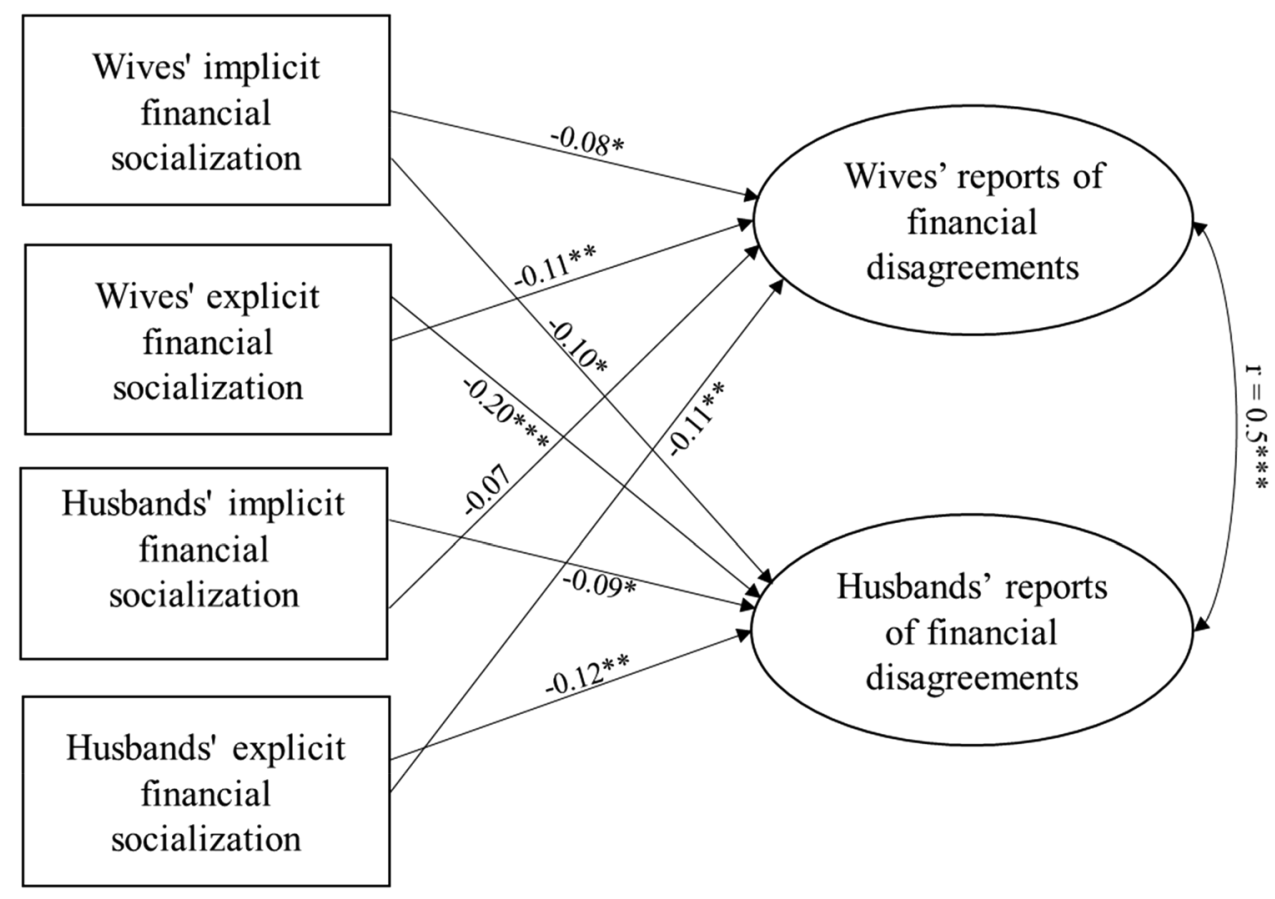

Data: Couple Relationships and Transition Experiences (CREATE), Wave 3

Notes. Standardized coefficients presented. Model fit: Chi-square $=2501.37(147), \mathrm{p}=.000 ; \mathrm{CFI}=$ 0.95 ; $\mathrm{RMSEA}=0.03$ (lower $\mathrm{CI}=0.025$, upper $\mathrm{CI}=0.035$ ).

$* \mathrm{p}<0.05 ; * * \mathrm{p}<0.01 ; * * * \mathrm{p}<0.001$ socialization scored significantly lower on the scale of financial disagreements than wives who reported no financial socialization; these relationships were statistically significant $(p<0.05)$. This means that women who experienced implicit financial socialization scored 0.08 standard deviations lower, and women who experienced explicit financial socialization scored 0.11 standard deviations lower, on the six-point financial disagreements scale when compared with women who reported having experienced no financial socialization whatsoever, notable differences. Similarly, husbands who reported implicit $(b=-0.09)$ or explicit $(b=-0.12)$ financial socialization scored significantly lower on the marital financial disagreements scale when compared with husbands who reported no financial socialization; these relationships were statistically significant $(p<0.05)$.

We further hypothesized that explicit socialization would be more strongly related to marital financial disagreements than implicit socialization. This hypothesis was supported by the reports of wives, but, interestingly, not by those of husbands. The standardized coefficient for explicit socialization $(b=-0.11)$ was larger than that for implicit socialization $(b=-0.08)$ for wives; this difference was statistically significant according to a post-estimation Wald test $(p<0.01)$. Explicit socialization, therefore, has a stronger association than implicit socialization for women's reports of marital financial disagreements. As with the results for wives, husbands' explicit socialization had a larger association $(b=-0.12)$ than implicit socialization $(b=-0.09)$ with husbands' reports of financial disagreements. However, this difference was not statistically significant according to a post-estimation Wald test.

We also found evidence of partner effects. Generally, spouses' childhood financial socialization was significantly and negatively related to reports of marital financial disagreements, independent of the respondents' own childhood financial socialization. For wives, husbands' explicit financial socialization was significantly related to lower scores on the scale of financial disagreements when compared with those of wives whose husbands reported no financial socialization $(b=-0.11, p<0.001)$. This means that women whose husbands had experienced explicit childhood financial socialization scored 0.11 standard deviations lower on the scale of financial disagreements than women whose husbands had reported no financial disagreements. However, husbands' reports of implicit financial socialization had a non-significant relationship with wives' reports of financial disagreements. For husbands, both wives' implicit $(b=-0.10)$ and explicit $(b=-0.20)$ financial socialization were significantly related to husbands' reports of financial disagreements $(p<0.05)$.

We found that both the respondents' own financial socialization and that of their partners were significant and notable when predicting marital financial disagreements. However, we did not find that one was more strongly associated with 
financial disagreements than the other. Although wives' explicit childhood financial socialization $(b=-0.20)$ had a larger standardized coefficient than husbands' own financial socialization $(b=-0.12)$, over one and a half times larger, when predicting husbands' reports of marital financial disagreements, these differences were not statistically significant according to post-estimation Wald tests. Similarly, husbands' financial socialization related equally to wives' reports of marital financial disagreements when compared with wives' own financial socialization.
Several control variables were significantly associated with reported marital financial disagreements for men and women (see Table 2). For women, having attended at least some college was significantly and positively associated with reported marital financial disagreements, net of other covariates $(b=0.09, p<0.05)$. Further, having a husband who reported having some college or more $(b=-0.14$, $p=0.001)$, having an annual household income of over $\$ 70,000(b=-0.09, p=0.02)$, and having a joint bank account with their husband $(b=-0.14, p=0.001)$ were

Table 2 APIM SEM Predicting Financial Disagreements among Newly-Married, Heterosexual Couples, 2018, United States ( $N=1,473)$

\begin{tabular}{|c|c|c|c|c|c|c|}
\hline & \multicolumn{3}{|c|}{ DV: wives' reports of financial disagreements } & \multicolumn{3}{|c|}{$\begin{array}{l}\text { DV: husbands' reports of financial disagree- } \\
\text { ments }\end{array}$} \\
\hline & Unstandardized & Standardized & $\mathrm{P}$ & Unstandardized & Standardized & $\mathrm{p}$ \\
\hline \multicolumn{7}{|l|}{ Childhood financial socialization } \\
\hline None (reference) & - & - & - & - & - & - \\
\hline Implicit & $-0.14(0.08)$ & -0.08 & 0.02 & $-0.16(0.08)$ & -0.09 & 0.04 \\
\hline Explicit & $-0.22(0.09)$ & -0.11 & 0.01 & $-0.22(0.08)$ & -0.12 & 0.01 \\
\hline Age & $-0.004(0.01)$ & -0.02 & 0.67 & $0.001(0.01)$ & 0.01 & 0.87 \\
\hline Previously married & $-0.14(0.13)$ & -0.04 & 0.26 & $-0.07(0.10)$ & -0.03 & 0.48 \\
\hline Some college or more & $0.20(0.10)$ & 0.09 & 0.04 & $-0.19(0.08)$ & -0.11 & 0.01 \\
\hline \multicolumn{7}{|l|}{ Race } \\
\hline White (reference) & - & - & - & - & - & - \\
\hline Black & $0.06(0.20)$ & 0.02 & 0.76 & $0.12(0.18)$ & 0.04 & 0.52 \\
\hline Latino & $-0.08(0.12)$ & -0.03 & 0.52 & $0.001(0.10)$ & 0.00 & 0.10 \\
\hline Other & $-0.19(0.10)$ & -0.07 & 0.06 & $0.06(0.09)$ & 0.02 & 0.53 \\
\hline Employed & $0.08(0.07)$ & 0.04 & 0.27 & $-0.06(0.10)$ & -0.02 & 0.58 \\
\hline \multicolumn{7}{|l|}{ Spouse characteristics } \\
\hline \multicolumn{7}{|l|}{ Childhood financial socialization } \\
\hline None (reference) & - & - & - & - & - & - \\
\hline Implicit & $-0.12(0.08)$ & -0.07 & 0.13 & $-0.16(0.08)$ & -0.10 & 0.04 \\
\hline Explicit & $-0.23(0.09)$ & -0.11 & 0.01 & $-0.35(0.08)$ & -0.20 & 0.00 \\
\hline Age & $0.003(0.01)$ & 0.02 & 0.72 & $-0.01(0.01)$ & -0.05 & 0.32 \\
\hline Previously married & $-0.03(0.11)$ & -0.01 & 0.78 & $0.05(0.11)$ & 0.02 & 0.67 \\
\hline Some college or more & $-0.29(0.09)$ & -0.14 & 0.001 & $0.18(0.09)$ & 0.09 & 0.04 \\
\hline \multicolumn{7}{|l|}{ Race } \\
\hline White (reference) & - & - & - & - & - & - \\
\hline Black & $0.02(0.19)$ & 0.01 & 0.91 & $-0.12(0.18)$ & -0.04 & 0.52 \\
\hline Latino & $0.10(0.13)$ & 0.04 & 0.43 & $-0.12(0.11)$ & -0.06 & 0.24 \\
\hline Other & $0.04(0.10)$ & 0.02 & 0.68 & $-0.23(0.08)$ & -0.10 & 0.01 \\
\hline Employed & $-0.05(0.11)$ & -0.01 & 0.67 & $0.08(0.07)$ & 0.04 & 0.25 \\
\hline \multicolumn{7}{|l|}{ Couple characteristics } \\
\hline Months married at wave one & $-0.001(0.01)$ & -0.01 & 0.81 & $-0.01(0.01)$ & -0.04 & 0.29 \\
\hline Number of children & $0.04(0.03)$ & 0.05 & 0.23 & $0.03(0.03)$ & 0.05 & 0.23 \\
\hline Annual household income over $\$ 70,000$ & -0.12 & -0.09 & 0.02 & $-0.09(0.07)$ & -0.06 & 0.17 \\
\hline Joint bank account & $-0.31(0.09)$ & -0.14 & 0.001 & $-0.23(0.08)$ & -0.11 & 0.004 \\
\hline
\end{tabular}

Data: Couple Relationships and Transition Experiences (CREATE), Wave 3

Standard errors in parentheses

Model fit: Chi-square $=2501.37(147), p=0.000 ; \mathrm{CFI}=0.95 ; \mathrm{RMSEA}=0.03$ (lower $\mathrm{CI}=0.025$, upper $\mathrm{CI}=0.035)$ 
significantly and negatively associated with reported marital financial disagreements for women.

For men, having some level of a college education or higher was significantly associated with lower scores on the scale of financial disagreements $(b=-0.11, p=0.01)$. Moreover, having a wife who had some level of a college or more was positively and significantly associated with financial disagreements $(b=0.09, p=0.04)$. Having a wife who was of a race or ethnicity other than Black or Latino was significantly and negatively related to financial disagreements when compared to having a wife who was White ( $b=-0.10, p=0.01)$. And, similar to women, having a joint bank account was shown to be significantly and negatively related to husbands' reports of marital financial disagreements $(b=-0.11, \mathrm{p}=0.004)$.

\section{Sensitivity Analyses}

To ensure confidence in our results, we estimated our presented models under four additional specifications (see the online Appendix). First, we included same-sex couples in APIM SEM models and randomly assigned same-sex partners as "partner one" or "partner two" (see Table A2). Second, we included respondents' reports of their parents arguing about finances as an additional control variable $(1=$ parents usually argued about finances; $0=$ parents did not usually argue about finances) to partially account for the quality or tone of the financial socialization (see Table A3). Third, we included a measure of the frequency of financial disagreements as the dependent variable rather than a scale. Here, we used responses to the question "How often in the last year have you had open disagreements about money with your spouse?", with the following response options $1=$ never; $2=$ once or twice; $3=$ a few times; $4=$ about once a month; $5=$ about once a week; $6=$ several times a week or more (see Table A4). Fourth, we included a measure of the quality of communication as a dependent variable rather than a scale (see Table A5). In doing so, we used responses to the question "How well are you and your spouse able to communicate about money?", with response options $1=$ extremely well; $2=$ very well; $3=$ okay; $4=$ not very well; $5=$ not well at all.

Specifications 1, 2, and 4 garnered nearly substantively identical results when compared to the presented findings. The only major difference between these specifications and the presented results is that partner one's implicit financial socialization was no longer significant in predicting their own reports of financial disagreements when including same-sex couples (specification 1) or measuring the quality of communication about finances (specification 4). Notably, the control variable indicating whether respondents' parents fought about finances was not significantly predictive of either of the partners' reports of financial disagreements. This may be because this variability had already been captured when we measured implicit financial socialization.

The results were different when we estimated a model using a measure of the frequency of financial disagreements as the dependent variable (see Table A4). In this specification, financial socialization was not significantly related to women's or men's reports of marital financial disagreements, regardless of whether it was implicit or explicit. Only one finding remained significant under this specification: wives' explicit financial socialization $(b=-0.13, p<0.01)$ was negatively and significantly related to husbands' reports of the frequency of financial disagreements. The lack of findings under this specification may relate to the multidimensional nature of financial disagreements. Perhaps financial socialization is not related to the frequency of disagreements because those who are financially socialized are more willing to discuss, rather than avoid, financial topics, increasing their exposure to disagreements. Meanwhile, those who have not been financially socialized may avoid discussing these topics where possible but disagree with their spouses more often when they arise in conversation. This interpretation is further supported by the significant results that we obtained by using quality of communication about finances as the dependent variable. The ways in which couples discuss finances - rather than how often they disagree about finances - appear to be particularly salient in the context of financial socialization.

\section{Discussion}

Using data from a nationally representative study of newlymarried couples in the United States, we examined the relationship between childhood financial socialization and marital financial disagreements. Although other studies have examined the role of childhood financial socialization among other behaviors and attitudes in childhood and adulthood (for a review, see Gudmunson and Danes 2011), this was the first known study to examine the role of childhood financial socialization in marriage.

Our study has served to deepen understanding about childhood financial socialization, offering several important findings. First, we found that childhood financial socialization was significantly and negatively related to marital financial disagreements for both men and women. Financial socialization in childhood may be protective against marital financial disagreements for several reasons. Most notably, financial socialization exposes individuals to models and scripts for navigating difficult topics within a marriage. Financial disagreements have been found to be "more pervasive, problematic, and recurrent, and remained unresolved" more often than other forms of disagreements (e.g., 
Papp et al. 2009, p. 91) and elicit poorer conflict resolution tactics when compared to most other types of marital disagreements (Dew and Dakin 2011). Therefore, children may heavily benefit from exposure to the models and skills that are taught through financial socialization. Furthermore, financial socialization in childhood is related to advantageous financial behaviors in adulthood (e.g., Hancock et al. 2013; Jorgensen et al. 2017). Consequently, we contend that an individual who has encountered financial socialization in some form is more likely to find themselves in better financial contexts in the future in which disagreements are less likely to occur.

Second, we found that, although both implicit and explicit financial socialization were negatively associated with financial disagreements, explicit financial socialization was more strongly related to financial disagreements than implicit financial socialization for women. Previous research has highlighted the importance of both forms of financial socialization (Gudmunson and Danes 2011). However, our study provides quantitative evidence that explicit financial socialization is especially important. This may be because explicit financial socialization is more likely to be positive and healthy. When parents deliberately teach their children about finance, these conversations are often calm and can even provide opportunities for bonding (LeBaron et al. 2018c).

Alternatively, implicit financial socialization experiences can be much more varied and can often involve children picking up on negative, unhealthy, and unintentional messages from their parents (LeBaron et al. 2018a; Solheim et al. 2011). Moreover, explicit teaching invites children into financial conversations, thereby increasing their experiences in discussing important matters as well as improving their communication skills. This finding has several policy implications as programs can teach parents how to effectively and intentionally teach their children financial skills. Our findings imply that this type of training would not only help children to learn to be more financially savvy but would also improve the quality of their marriages when they reach adulthood.

Third, we found evidence of partner effects. For both women and men, their spouses' explicit financial socialization was significantly and negatively associated with reported marital disagreements, independently of the respondent's own financial socialization. These results suggest that spouses' levels of skill and comfort in discussing finances are especially impactful. Understanding these partner effects and their mechanisms would constitute a fruitful area for future research.

Notably, we found minimal gender differences. Money is closely associated with gendered norms (Cherlin 2014; LeBaron et al. 2018b). Although women have been entering the workforce in large numbers since the 1960s (England
2010), the breadwinner model remains salient and stubbornly pervasive (e.g., Cherlin 2014). Supporting this view, previous studies have found that marital financial disagreements are particularly significant for husbands (Dew et al. 2012). In fact, financial disagreements were the only type of disagreement that could reliably predict divorce among husbands, whereas several types of disagreements (i.e., sex and finances) predicted divorce among wives (Dew et al. 2012). In contrast, our results were substantively similar for men and women. Perhaps this is because financial socialization is associated with 'gender-neutral' aspects of financial communication within marriages but does not change the perceived meaning of these arguments after the fact. Perhaps it is the post-argument meaning that is gendered and especially meaningful for men. We conclude that parents should explicitly teach all of their children about finance, regardless of their child's gender.

Our results have several implications for both research and policy. Our findings point to the important role that financial socialization plays in marital contexts. Future studies would benefit from undertaking systematic examinations of the impact of financial socialization in childhood on marital processes and outcomes. Moreover, our results suggest that encouraging and supporting financial socialization can weaken the documented weight of financial disagreements or conflict within marriages (e.g., Amato and Rogers 1997; Britt and Huston 2012; Dew and Dakin 2011; Dew et al. 2012; Gudmunson et al. 2007; Hill et al. 2017). Furthermore, our findings highlight the important role of explicit financial socialization. These results suggest that children would benefit from efforts (e.g., parenting programs) that teach and encourage parents to directly and purposively discuss finances with their children.

Our study is not without limitations. Most notably, we are limited by the ambiguity in our financial socialization measure. Respondents could select any number of boxes from the four available response categories - "no financial socialization"; "parents fought about finances"; "implicit learning"; and "explicit learning" - and this could, in turn, have clouded the results. For example, implicit financial socialization does not necessarily denote explicit financial socialization. Conversely, participants who experienced explicit financial socialization likely also experienced implicit financial socialization (Gudmunson and Danes 2011). We, like past scholars (e.g., LeBaron et al., in press), see this as a meaningful direction for future research: the development of clearer, more nuanced measures of childhood financial socialization.

Further, our study cannot account for the quality of the financial socialization that our respondents experienced. Parents may directly teach their children ineffective or unhealthy financial skills. Alternatively, and, likely, more frequently, parents may set a less-than-ideal example for 
their children to follow. The CREATE data set does not provide the information that we would need to be able to parse out such nuance. Finally, because measurement invariance was not established between husbands and wives on financial disagreement latent variables, we cannot know if the structural differences that we observed were due to construct associations or measurement differences. Individuals who undertake future research into this area should explore the ways in which financial disagreements may be measured differently among husbands versus wives and how such differences may impact the relationships between financial socialization and marital financial disagreements.

Despite these limitations, this study provides a first step toward exploring the connections between financial socialization in childhood and marital processes. Our study points to the importance of financial socialization for spousal interactions; as such, we argue that the further examination of these relationships is an important area for future research.

\section{Compliance with Ethical Standards}

Conflict of interest The authors declare that they have no conflict of interest.

Ethical Approval Our study utilized secondary data from the CREATE data set collected by scholars at Brigham Young university: Jeremy Yorgason (PI), Erin Holmes (Co-PI), and Spencer James (Co-PI). The CREATE project was approved by the IRB committee at Brigham Young University.

Informed Consent All respondents or participants in the data (CREATE) provided informed consent.

\section{References}

Addo, F. R., \& Sassler, S. (2010). Financial arrangements and relationship quality in low-income couples. Family Relations, 59(4), 408-423. https://doi.org/10.1111/j.1741-3729.2010.00612.x.

Amato, P. R., \& Previti, D. (2003). People's reasons for divorcing: Gender, social class, the life course, and adjustment. Journal of Family Issues, 24(5), 602-626. https://doi.org/10.1177/01925 $13 \mathrm{X} 03254507$.

Amato, P. R., \& Rogers, S. J. (1997). A longitudinal study of marital problems and subsequent divorce. Journal of Marriage and the Family, 59(3), 612-624. https://doi.org/10.2307/353949.

Britt, S. L., \& Huston, S. J. (2012). The role of money arguments in marriage. Journal of family and Economic Issues, 33(4), 464-476. https://doi.org/10.1007/s10834-012-9304-5.

Cherlin, A. J. (2014). Labor's love lost: the rise and fall of the workingclass family in America. Russell Sage Foundation. www.jstor.org/ stable/10.7758/9781610448444.

Curran, M. A., Parrott, E., Ahn, S. Y., Serido, J., \& Shim, S. (2018). Young adults' life outcomes and well-being: Perceived financial socialization from parents, the romantic partner, and young adults' own financial behaviors. Journal of Family and Economic Issues, 39(3), 445-456. https://doi.org/10.1007/s10834-018-9572-9.
Dew, J., \& Dakin, J. (2011). Financial disagreements and marital conflict tactics. Journal of Financial Therapy. https://doi. org/10.4148/jft.v2i1.1414.

Dew, J., Britt, S., \& Huston, S. (2012). Examining the relationship between financial issues and divorce. Family Relations, 61(4), 615-628. https://doi.org/10.1111/j.1741-3729.2012.00715.x.

England, P. (2010). The gender revolution: Uneven and stalled. Gender \& Society, 24(2), 149-166. https://doi.org/10.1177/08912 43210361475.

Gibson-Davis, C. M. (2009). Money, marriage, and children: Testing the financial expectations and family formation theory. Journal of Marriage and Family, 71(1), 146-160. https://doi.org/10.11 11/j.1741-3737.2008.00586.x.

Grinstein-Weiss, M., Spader, J., Yeo, Y. H., Taylor, A., \& Freeze, E. B. (2011). Parental transfer of financial knowledge and later credit outcomes among low-and moderate-income homeowners. Children and Youth Services Review, 33(1), 78-85. https://doi. org/10.1016/j.childyouth.2010.08.015.

Grusec, J. E., \& Hastings, P. D. (Eds.). (2014). Handbook of socialization: Theory and research. Guilford Publications.ISBN: 1593853327.

Gudmunson, C. G., \& Danes, S. M. (2011). Family financial socialization: Theory and critical review. Journal of Family and Economic Issues, 32(4), 644-667. https://doi.org/10.1007/s1083 4-011-9275-y.

Gudmunson, C. G., Beutler, I. F., Israelsen, C. L., McCoy, J. K., \& Hill, E. J. (2007). Linking financial strain to marital instability: Examining the roles of emotional distress and marital interaction. Journal of Family and Economic Issues, 28(3), 357-376. https://doi.org/10.1007/s10834-007-9074-7.

Hancock, A. M., Jorgensen, B. L., \& Swanson, M. S. (2013). College students and credit card use: The role of parents, work experience, financial knowledge, and credit card attitudes. Journal of Family and Economic Issues, 34(4), 369-381. https://doi. org/10.1007/s10834-012-9338-8.

Hibbert, J., Beutler, I., \& Martin, T. (2004). Financial prudence and next generation financial strain. Journal of Financial Counseling and Planning, 15(2), 51-59. https://ssrn.com/abstr act $=2255181$

Hill, E. J., Allsop, D. B., LeBaron, A. B., \& Bean, R. A. (2017). How do money, sex, and stress influence marital instability? Journal of Financial Therapy, 8(1), 3. https://doi. org/10.4148/1944-9771.1135.

Hu, L.-T., \& Bentler, P. M. (1999). Cutoff criteria for fit indexes in covariance structure analysis: Conventional criteria versus new alternatives. Structural Equation Modeling, 6(1), 1-55. https:// doi.org/10.1080/10705519909540118.

Johnson, E., \& Sherraden, M. S. (2007). From financial literacy to financial capability among youth. Journal of Sociology \& Social Welfare, 34, 119-146.

Jorgensen, B. L., Rappleyea, D. L., Schweichler, J. T., Fang, X., \& Moran, M. E. (2017). The financial behavior of emerging adults: A family financial socialization approach. Journal of Family and Economic Issues, 38(1), 57-69. https://doi.org/10.1007/s1083 4-015-9481-0.

Jorgensen, B. L., \& Savla, J. (2010). Financial literacy of young adults: The importance of parental socialization. Family Relations, 59(4), 465-478. https://doi.org/10.1111/j.1741-3729.2010.00616.x.

Kenny, D. A., Kashy, D. A., \& Cook, W. L. (2006). Dyadic Data Analysis. Guilford press.

Kim, J., \& Chatterjee, S. (2013). Childhood financial socialization and young adults' financial management. Journal of Financial Counseling and Planning, 24(1), 61.

Koonce, J. C., Mimura, Y., Mauldin, T. A., Rupured, A. M., \& Jordan, J. (2008) Financial information: Is it related to savings and investing knowledge and financial behavior of teenagers? Journal of 
Financial Counseling and Planning, 19, 19-28. https://ssrn.com/ abstract $=2226475$.

LeBaron, A. B., Hill, E. J., Rosa, C. M., Spencer, T. J., Marks, L. D., \& Powell, J. T. (2018a). I wish: Multigenerational regrets and reflections on teaching children about money. Journal of Family and Economic Issues, 39(2), 220-232. https://doi.org/10.1007/ s10834-017-9556-1.

LeBaron, A. B., Holmes, E. K., Yorgason, J. B., Hill, E. J., \& Allsop, D. B. (2018b). Feminism and couple finance: Power as a mediator between financial processes and relationship outcomes. Sex Roles, 81(3-4), 140-156. https://doi.org/10.1007/s11199-018-0986-5.

LeBaron, A. B., Hill, E. J., Rosa, C. M., \& Marks, L. D. (2018c). Whats and hows of family financial socialization: Retrospective reports of Millennials and their parents and grandparents. Family Relations, 67(4), 497-509. https://doi.org/10.1111/fare.12335.

LeBaron, A. B., Holmes, E. K., Jorgensen, B. L., \& Bean, R. A. (In press). Parental financial education during childhood and financial behaviors of emerging adults. Journal of Financial Counseling and Planning.

LeBaron, A. B., Marks, L. D., Rosa, C. M., \& Hill, E. J. (2020). Can we talk about money?. Financial socialization through parentchild financial discussion: Emerging Adulthood. https://doi. org/10.1177/2167696820902673.

McCarthy, G., \& Maughan, B. (2010). Negative childhood experiences and adult love relationships: The role of internal working models of attachment. Attachment \& Human Development, 12(5), 445461. https://doi.org/10.1080/14616734.2010.501968.

Muthén, L. K., \& Muthén, B. O. (2017). Mplus: Statistical Analysis with Latent Variables: User's Guide (Version 8). Los Angeles, CA: Authors.

Newman, D. A. (2003). Longitudinal modeling with randomly and systematically missing data: A simulation of ad hoc, maximum likelihood, and multiple imputation techniques. Organizational Research Methods, 6(3), 328-362. https://doi.org/10.1177/10944 28103254673.

Norvilitis, J. M., \& MacLean, M. G. (2010). The role of parents in college students' financial behaviors and attitudes. Journal of Economic Psychology, 31(1), 55-63. https://doi.org/10.1016/j. joep.2009.10.003.

Papp, L. M., Cummings, E. M., \& Goeke-Morey, M. C. (2009). For richer, for poorer: Money as a topic of marital conflict in the home. Family Relations, 58(1), 91-103. https://doi.org/10.111 1/j.1741-3729.2008.00537.x.

Rosa, C. M., Marks, L. D., LeBaron, A. B., \& Hill, E. J. (2018). Multigenerational Modeling of Money Management. Journal of Financial Therapy, 9(2), 5 .

Serido, J., Curran, M. J., Wilmarth, M., Ahn, S. Y., Shim, S., \& Ballard, J. (2015). The unique role of parents and romantic partners on college students' financial attitudes and behaviors. Family Relations, 64(5), 696-710. https://doi.org/10.1111/fare.12164.

Serido, J., \& Deenanath, V (2016) Financial parenting: Promoting financial self-reliance of young consumers. In Handbook of Consumer Finance Research (pp 291-300). Springer, Cham. Doi: 10.1007/978-3-319-28887-1_24.

Solheim, C. A., Zuiker, V. S., \& Levchenko, P. (2011). Financial socialization family pathways: Reflections from college students' narratives. Family Science Review, 16(2), 97-112.

Stanley, S. M., Markman, H. J., \& Whitton, S. W. (2002). Communication, conflict, and commitment: Insights on the foundations of relationship success from a national survey. Family Process, 41(4), 659-675. https://doi.org/10.1111/j.1545-5300.2002.00659 .x.

Truant, G. S., Herscovitch, J., \& Lohrenz, J. G. (1987). The Relationship of Childhood Experience to the Quality of Marriage. The Canadian Journal of Psychiatry, 32(2), 87-92. https://doi. org/10.1177/070674378703200202.

Ward, S. (1974). Consumer socialization. Journal of Consumer Research, 1(2), 1-14. https://doi.org/10.1086/208584.

Webley, P., \& Nyhus, E. K. (2006). Parents' influence on children's future orientation and saving. Journal of Economic Psychology, 27(1), 140-164. https://doi.org/10.1016/j.joep.2005.06.016.

Yorgason, J. B., James, S. L., \& Holmes, E. K. (2018). Couple relationships and transition experiences (CREATE) codebook (wave 1). Provo, UT: School of Family Life, Brigham Young University.

Publisher's Note Springer Nature remains neutral with regard to jurisdictional claims in published maps and institutional affiliations. 